\section{Liquor-Polymerase-Kettenreaktion (Liquor-PCR)}

T. O. Kleine

Institut für Laboratoriumsmedizin und Pathobiochemie, Molekulare Diagnostik Standort Marburg Referenzlabor für Liquordiagnostik, UKGM Universitätsklinikum Gießen und Marburg, Marburg, Deutschland

\section{Synonym(e) PCR}

Englischer Begriff polymerase chain reaction (PCR) in cerebrospinal fluid (CSF)

Definition Liquor-PCR infektiöser Genome mittels „outer“ und „nested“ Primers ermöglicht Diagnostik früher oder schwebender Infektionen des Zentralnervensystems (ZNS); $\checkmark$ PCR (Polymerase-Kettenreaktion).
Beschreibung Detektion infektiöser Genome in CSF mittels PCR ist zeitlich beschränkt durch frühe ( $>7$ Tage) intrathekale Synthese spezifischer oligoklonaler Antikörper gegen infektiöses Agens selbst bei schwerer systemischer Immundefizienz. Höhere analytische Effizienz durch Kombination von PCR und Detektion spezifischer oligoklonaler Banden bei der Diagnostik viraler und chronischer Infektionen des ZNS.

\section{Literatur}

Sindic CJM, van Antwerpen MP, Goffette S (2003) Clinical relevance of polymerase chain reaction (PCR) assays and antigen-driven immunoblots for the diagnosis of neurological infectious diseases. Brain Res Bull 61:299-308 